\title{
Application of Cohesion Theory in Reading Comprehension of CET-4
}

\author{
Chunxia $\mathrm{Fu}^{1}$ \\ ${ }^{1}$ Faculty of Foreign Studies, Yangtze University College of Arts and Sciences, Jingzhou, Hubei, China, 434020 \\ Correspondence: Chunxia Fu, Faculty of Foreign Studies, Yangtze University College of Arts and Sciences, \\ Jingzhou, Hubei, China.
}

Received: March 5, 2020

Accepted: March 23, 2020

Online Published: March 24, 2020

doi: 10.5539/elt.v13n4p86

URL: https://doi.org/10.5539/elt.v13n4p86

\begin{abstract}
Cohesion Theory of Halliday and Hasan has been widely applied in different parts of language teaching. As many cohesive devices are used in language, it's very necessary for language learners to understand and identify those devices. Now in China, a large number of college students have to take part in the CET-4 test every year. Thus, it is of great significance that some effective strategies can be applied in the test and help more students pass the test easily. Cohesion Theory and cohesive devices may be such strategies and they are important for the improvement of reading comprehension of CET-4. This article is aiming to use the CET-4 test papers in June 2019 as examples to illustrate that Cohesion Theory can be applied in reading comprehension of CET-4 with great effectiveness.
\end{abstract}

Keywords: Cohesion Theory, reading comprehension, CET-4, China

\section{Introduction}

Nowadays, the Cohesion Theory is applied widely in the EFL teaching such as in reading, writing, listening and speaking. However, there is not much research on the application of Cohesion Theory in CET-4(College English Test Band 4). Applying the Cohesion theory is definitely an effective approach in the test. According to Halliday and Hasan(1976), two aspects of Cohesion Theory were mainly included, one is grammatical cohesion and the other is lexical cohesion. In the passages of reading comprehension in CET-4, many cohesive devices can be used. If the students have the relevant knowledge, they will have a better understanding of those passages and are more likely to get the right choices, thus get high scores. The purpose of this article is to illustrate that Cohesion Theory can be definitely applied in reading comprehension of CET-4 by analyzing the examples of CET-4 test papers in June 2019. The application of Cohesion theory in CET-4 is of practical significance for both the teachers and the college students during the CET-4 preparation.

\section{Cohesion Theory}

The book Cohesion in English of Halliday and Hasan has been regarded as the symbol of the first introduction of Cohesion Theory. And they have made significant contribution to the research field on cohesion.

According to Halliday and Hasan, cohesion is a semantic relation which makes a passage or a text as a whole and united one, and it combines all the elements of the text in order to get a single new unit. Besides this, cohesion is also a concrete means of obtaining unity and forms a discourse or a text, distinguishing it from a non-text one. It also reflects the unity of the text. Besides, they also systematize their concepts and further classify cohesion into several distinct categories. According to them, cohesion can be mainly divided into two categories. One is grammatical cohesion which includes reference, substitution, ellipsis and conjunction, the other is lexical cohesion which includes reiteration and collocation.

There are four cohesive devices from the grammatical aspect and two cohesive devices from the lexical aspect. According to Halliday and Hasan, reference means that an element in the text has relation with something else in the same text. Words are not to be interpreted semantically in their own right. They make reference to something else in their interpretation. While learning the language, the learners will try to get the signs of reference to look back or forward to find what it means. Substitution is a replacement of one item by another, which can be words or phrases. The substitute item should have the grammatical function, it may function as a noun, a verb or a clause. Ellipsis refers to the omission of a word or part of a sentence in a text. It may refer to "something left unsaid", but it implies "being understood". Conjunction does not have cohesion itself but it indicates cohesion indirectly by the virtue of the specific meaning. Lexical cohesion is an approach to achieve cohesion in terms of 
vocabulary selection. It is a way to set up the cohesion in a text by using the same presupposed word or related words, to express a sense of integration in the text. Reiteration is a lexical device which means the repetition of lexical items. Collocation has to do with the relationship between words on that they often occur in the same context.

In reading comprehension, if the learners can catch the tangible network from the perspective of cohesive approaches, the meaning of the whole text then can be understood. The English learners or test-takers then can have a better understanding of the texts in reading comprehension, and then make the right choice and have high scores in the tests.

\section{Application of Cohesion Theory in Reading Comprehension of CET-4}

CET-4 mainly consists of four parts: writing(15\%), listening comprehension(35\%), reading comprehension(35\%) and Paragraph translation from Chinese to English(15\%). Reading comprehension, which accounts for $35 \%$ of the total score, is one of the most important parts in CET-4. Therefore, the performance in reading comprehension is somehow a decisive factor of the whole test. The research of the effective ways to improve the reading comprehension can be very meaningful and worthwhile.

There are three parts of reading comprehension in CET-4, one is completing the banked cloze, which accounts for $5 \%$ of the total score, the second is matching, which accounts for $10 \%$ of the total score, and the last one is reading in depth, which accounts for $20 \%$ of the total score. The application of Cohesion Theory in reading comprehension is analyzed respectively from those three parts. And the grammatical devices and lexical devices are applied for the better understanding of the passages. The CET-4 test papers in June 2019 are used here as examples for analysis.

\subsection{Application of Cohesion Theory in Banked Cloze}

Banked Cloze is the first part of reading comprehension in CET-4. In that section, there is a passage with ten blanks. The test-takers are required to select one word for each blank from a list of choices given in a word bank following the passage. There are fifteen choices in the word bank containing prompts and distractors. They may not use any of the words in the bank more than once. In order to understand the unity of the passage and choose the right words to fill in the blanks, the cohesive clues can be very useful. One Banked Cloze in CET-4 test paper in June 2019 is used here as an example to illustrate that the cohesive devices can be identified as contextual clues for making the right choices.

Table 1. A Banked Cloze in CET-4 Test Paper in June 2019

The passage is about self-driving vehicles and self-driving technology in America.
A) bid
B) contrast
C) deputy
D) dominance
E) fleets
F) knots
G) legislation
H)migrated
I) replace
J) represent
k) restrictive
L) reward
M) significant
N) sponsor
O) transmitted

Table 2. Cohesive Devices and Clues Applied in the Banked Cloze

\begin{tabular}{llll}
\hline Blanks & The right answer & Cohesive devices & Cohesive clues \\
\hline No.26 & migrated & reiteration & moved---migrate \\
No.27 & bid & collocation & the best place---in a bid to \\
No.28 & legislation & collocation & lawmakers---legislation \\
No.29 & dominance & reiteration & leadership---dominance \\
No.30 & replace & reiteration & under attack---replace \\
No.31 & sponsor & collocation & bills---sponsor \\
No.32 & represent & collocation & represent---update \\
No.33 & fleets & reiteration & groups---fleets \\
No.34 & contrast & conjunction & in contrast \\
No.35 & restrictive & collocation & ban---restrictive \\
\hline
\end{tabular}

In this Banked Cloze, almost every blank can get some clues from the aspect of cohesive devices. Both the grammatical cohesive devices and lexical cohesive devices can be used. Three types of cohesive devices can be applied to figure out each blank and have a comprehensive understanding of this passage. For example, 
reiteration can be applied in No. 26, as we can see the word "moved" in the former sentence, the word used in this blank should have the similar meaning with "moved", thus the word "migrated" can be easily chosen from the word bank. The two words are synonyms. The reiteration can also be used for other blanks as listed in the table. Collocation as another cohesive device can also be applied, taking No.28 as an example, "Michigan lawmakers" is the subject in the sentence, a lawmaker refers a person who writes and passes laws, especially the one who is a member of a legislature. And legislation consists of a law or laws passed by a government, so these two words "lawmakers" and "legislation" often occur in the same context, and this will be cohesive in a context. "Lawmakers" can be the clue for filling the blank with "legislation". There are also some other examples of collocation in this passage. Meanwhile, conjunction can be used as a cohesive clue for No. 34. "In contrast" is an adversative conjunction to suggest the different policies between Michigan and California. In fact, almost each blank can get the right word with the cohesive clues as listed in Table 2, which indicates that the cohesive devices, no matter from the grammatical aspect or lexical aspect, can be applied effectively in the Banked Cloze in CET-4.

\subsection{Application of Cohesion Theory in Matching}

In the section of Matching in CET-4, there are ten statements attached to a long passage which consists of more than 10 paragraphs. Each statement contains information given in one of the paragraphs. The students have to identify the paragraph from which the information is derived. The CET-4 test paper in June 2019 is used here as an example to illustration that the cohesive devices can be identified as contextual clues for matching the right paragraph, and the detailed information has been listed in Table 3 and Table 4.

Table 3. Statement No.36 and Corresponding Information in Matched Paragraph

36. Unemployed young men are more likely to live with their parents than the employed.

H. Employed young men are much less likely to live at home than young men without a job.

The cohesive devices are not used alone, instead sometimes they are used interactively. Take statement No.36 in Table 3 as an example, "Unemployed young men" in the statement has the similar meaning with "young men without a job" in paragraph $\mathrm{H}$, as reiteration is applied here. "The employed" in the statement refers to "Employed young men" in paragraph $\mathrm{H}$, as ellipsis device is applied here. And "more likely" in the statement suggests comparative reference to "less likely" in paragraph H. From all the cohesive consideration, we can definitely match the statement No.36 with paragraph $\mathrm{H}$, and that is the right matching.

Table 4. Statements, Cohesive Devices and Clues in Matched Paragraph

\begin{tabular}{|c|c|c|}
\hline Statements & Cohesive devices & Cohesive clues(statement---sentence in the paragraph) \\
\hline \multirow{3}{*}{ No.36 } & reiteration & "unemployed young men"---“young men without a job" \\
\hline & ellipsis & "the employed"---"employed young men" \\
\hline & comparative reference & "more likely"---"less likely" \\
\hline No.37 & reiteration & $\begin{array}{l}\text { "men aged } 18 \text { to } 34 \text { living with their parents"---"men aged } 18 \\
\text { to } 34 \text { living in the home of their parent(s)" }\end{array}$ \\
\hline \multirow{2}{*}{ No.38 } & \multirow{2}{*}{ reiteration } & "greatly decreased"---“substantially fallen" \\
\hline & & "in the past three decades"---"since 1990" \\
\hline \multirow{2}{*}{ No.39 } & \multirow{2}{*}{ reiteration } & "around the mid-20th century"---“around 1960" \\
\hline & & "only one-in-five"---“only 20 percent" \\
\hline No.40 & reiteration & $\begin{array}{l}\text { "live independently of their parents"---"establish their own } \\
\text { households" }\end{array}$ \\
\hline No.41 & comparative reference & "less likely"---“more likely" \\
\hline No.42 & reiteration & "delayed marriage"---"delayed marriage" \\
\hline No.43 & reiteration & "grown"-“risen", "decreased pay"---“wages have fallen" \\
\hline No.44 & reiteration & $\begin{array}{l}\text { "the rise in the number of college students"---"college } \\
\text { enrollments expanded" }\end{array}$ \\
\hline No.45 & reiteration & "married late"---"the postponement of marriage" \\
\hline
\end{tabular}


As in Table 4, reiteration can be mainly applied for matching the statement with the right paragraph. three types of reiteration approach are used here: (1) repeating the same word; (2) using a synonym or near-synonym, (3) using a superordinate. Repeating the same word and using a synonym or near-synonym are mostly occurring, and using a superordinate occurs only once in statement No.40. "live independently of their parents" may include many possibilities, and "establish their own households" is one of such possibilities. There are so many same or similar expressions appearing in the statements and some sentences in the passage, and cohesive approaches can be used for identifying and matching work. With so many same or similar expressions being matched under the cohesion device of reiteration, the matching then can be made definitely correct in this reading comprehension part.

\subsection{Application of Cohesion Theory in Reading in Depth}

There are 2 passages in the section of Reading in Depth. Each passage is followed by some questions or unfinished statements. For each of them there are four choices. The students should decide on the best choice. One passage from the CET-4 test paper in June 2019 is also used here as an example to illustrate that the cohesive devices can be identified as cohesive clues for choosing the best choice, and the detailed information has been listed in Table 5. This passage is about the survey on women seeking leadership roles.

Table 5. Questions, Cohesive Devices and Clues in the Passage

\begin{tabular}{|c|c|c|}
\hline Questions & Cohesive devices & Cohesive clues(right choice---sentence in the paragraph) \\
\hline No.46 & reiteration & "intelligent" ---"intelligence", "innovative"---“innovation" \\
\hline No.47 & reiteration & "family duties"---“career interruptions related to motherhood" \\
\hline No.48 & reiteration & "Gender bias"---“a double standard for women" \\
\hline No.49 & reiteration & "opposing opinions"---"the public is divided" \\
\hline No.50 & reiteration & $\begin{array}{l}\text { "A woman in the highest position of government" ---"a female } \\
\text { president in their lifetime" }\end{array}$ \\
\hline
\end{tabular}

As stated in Table 5, reiteration is applied here as a cohesive device to identifying the right sentence and matching the right choice in all the questions. In Question No. 46, as the meaning of "intelligent" and "innovative" is almost the same to "intelligence" and "innovation" except for one is the adjective and the other is the noun. In Question No. 47, "family duties" includes a lot of duties, and the duty as a mother is one of them, so the approach of reiteration "using a superordinate" is applied here. In Question No. 48, "Gender bias" indicates that women aren't treated equally and people have different standards for women. In Question No. 49, people have "opposing opinions" indicates that the public's opinions are quite different, even opposing to each other, so they are similar expressions. In Question No. 50, "a female president" refers to a woman in the highest position of government. The meaning is similarly stated, and reiteration is also applied here.

From the analysis of the passage in Reading in Depth, we can clearly draw a conclusion that reiteration can not only be used for figuring out the right choice, but it can also help the students quickly find the corresponding sentence in the passage where the answer lies in. The first three approaches of reiteration are commonly used in this part of the reading comprehension. The cohesion theory and cohesive devices are useful not only in understanding the passage, but also in figuring out the right choice during the reading comprehension.

\section{Conclusion}

From the examples and analysis above, we know that the reading comprehension can be done efficiently by applying the cohesive devices. We also know that the cohesive devices are not always applied alone; instead both the grammatical devices and lexical devices are usually applied interactively. This interactive application can be of great significance in reading comprehension. Not only are they useful for the students to acquire the right understanding and interpretation of the passages, but also helpful for the students to identify the answers more quickly; thus, the students can save time for other parts of the CET-4 test. All these factors are helpful for the students to perform well in the CET-4 test. In fact, besides the CET-4 test papers in June 2019 which are used here as examples, reading comprehension of other CET-4 tests can aslo be done with the application of Cohesion Theory. Hopefully, the approach of applying Cohesion Theory can also be of practical importance for both the teachers and the students in CET-4 instruction and preparation. On the one hand, the teachers can apply the Cohesion Theory as a guidance in CET-4 test instruction. On the other hand, the students can use those cohesive approaches in reading comprehension in CET-4 test. If the college students apply the cohesive devices frequently during the reading comprehension, they will make greater progress in their language acquisition in the long term and perform better in more difficult tests such as CET-6. 


\section{References}

Esther Geva, Fataneh Farnia. (2012). Developmental Changes in the Nature of Language Proficiency and Reading Fluency Paint a More Complex View of Reading Comprehension in ELL and EL1. Reading and Writing, 25(08), 1819-1845. https://doi.org/ 10.1007/s11145-011-9333-8.

Halliday, M. A. K., \& Hasan, R. (1976). Cohesion in English. London: Longman.

Johnson, K. (2002). An Introduction to Foreign Language Learning and Teaching. Beijing: Foreign Language Teaching and Research Press.

Katya Goussakova. (2016). Teaching and Learning English Grammar: Research Findings and Future Directions. System, 59, 133-135. https://doi.org/ 10.1016/j.system.2016.04.012.

Krashen, S. (1981). Second Language Acquisition and Second Language Learning. Oxford: Pergamon Press.

\section{Copyrights}

Copyright for this article is retained by the author(s), with first publication rights granted to the journal.

This is an open-access article distributed under the terms and conditions of the Creative Commons Attribution license (http://creativecommons.org/licenses/by/4.0/). 